\title{
Remission of Behcet's disease with anti-tumor necrosis factor monoclonal antibody therapy: a case report Salvatore Gulli ${ }^{1}$, Carlo Arrigo1, Loredana Bocchino1, Lucia Morgante ${ }^{1}$, Donatella Sangari ${ }^{1}$, Irene Castagna ${ }^{2}$ and Gian Filippo Bagnato*1
}

\author{
Address: ${ }^{1}$ Unit of Rheumatology, Department of Internal Medicine, Azienda Ospedaliera Universitaria "Policlinico G. Martino" and Universita' \\ degli Studi di Messina, Via Consolare Valeria n.12, 98100 Messina, Italy and 2Unit of Ophthalmology, Department of Ophthalmology, Azienda \\ Ospedaliera Universitaria "Policlinico G. Martino" and Universita' degli Studi di Messina, Via Consolare Valeria n.12, 98100 Messina, Italy \\ Email: Salvatore Gulli - salvatoregulli2@virgilio.it; Carlo Arrigo - carrigo@inwind.it; Loredana Bocchino - lobo73@inwind.it; \\ Lucia Morgante - luciamorgante@libero.it; Donatella Sangari - donatella.sangari@tiscali.it; Irene Castagna - castagna@unime.it; Gian \\ Filippo Bagnato* - bagnato@unime.it \\ * Corresponding author
}

This article is available from: http://www.biomedcentral.com/I47/-2474/4/19

(C) 2003 Gulli et al; licensee BioMed Central Ltd. This is an Open Access article: verbatim copying and redistribution of this article are permitted in all media for any purpose, provided this notice is preserved along with the article's original URL.

\begin{abstract}
Background: Behcet's disease (BD) is a chronic relapsing multisystem inflammatory disorder with mucocutaneous, ocular, articular, vascular, gastrointestinal and central nervous system manifestations. Tumor necrosis factor (TNF)-alpha is believed to play a pivotal role in BD. Therapeutic blockade of the activity of TNF has been successfully given in a short course of therapy with favorable effects in patients with $B D$ refractory to conventional immunosuppressive drugs. We aimed to find out whether a 12-month treatment with infliximab, a chimeric monoclonal antibody to TNF-alpha, had any beneficial effect in reducing relapses of a patient with long-standing $B D$ refractory to conventional immunosuppressive drugs.
\end{abstract}

Case presentation: A 54 year-old-woman with a 35-year history of BD with orogenital ulcerations, arthritis in the right knee and retinal lesions compatible with vasculitis received infliximab, $5 \mathrm{mg} / \mathrm{kg}$ by a two-hour intravenous infusion. Symptoms improved within 24 hours and eight days later the genital and oral ulcers healed as well as the arthritis in the right knee subsided. The retinal infiltrates completely resolved within 10 days. The infusions were repeated at weeks 2 , $6,14,22$ and then every 8 weeks. The patient was able to return to her domestic daily life. No exacerbation of the mucocutaneous ocular or arthritic symptoms occurred during the treatment period.

Conclusions: Previous studies have suggested that infliximab given in a short course of treatment is effective in inducing remission of severe mucocutaneous, gastrointestinal and ocular manifestations of BD. Our patient received a 12-month infliximab treatment showing a favorable effect on remission of $B D$ manifestations.

The long-term infliximab treatment appears as a new therapeutic option for patients with active $\mathrm{BD}$ who failed to respond to conventional immunosuppressive agents. 


\section{Background}

Behcet's disease (BD) is a chronic relapsing multisystem inflammatory disorder that causes orogenital ulcerations, skin lesions, intraocular inflammation (uveitis and retinal vasculitis) and less commonly arthritic, vascular, gastrointestinal and neurologic manifestations $[1,2]$.

The enhanced inflammatory reaction in $\mathrm{BD}$ appears to be mediated by cytokines derived from $\mathrm{T}$ helper type I lymphocytes, including tumor necrosis factor (TNF)-alpha [3].

TNF-alpha is produced by monocytes as part of the inflammatory cascade in BD and concentrations of TNF and soluble TNF receptors are increased in the serum of patients with the active disease [4].

It has been demonstrated that the T lymphocytes expressing the gammadelta receptor in $\mathrm{BD}$ are activated in vivo and produce increased amounts of TNF-alpha and interferon-gamma compared with healthy controls [5].

TNF-alpha and interleukin-8 might increase the expression of the CD11b-CD18 constitutively present on the polymorphonuclear neutrophils membrane and facilitate their rolling and diapedesis through the vascular endothelial wall $[2,6]$.

Therapeutic blockade of the activity of TNF has been successfully employed to treat Crohn's disease and rheumatoid arthritis, two other Th-1 mediated disorders [7].

Recently a short-term anti-TNF treatment was given with favorable effects in patients with BD refractory to conventional immunosuppressive drugs [8-10].

We aimed to find out whether a 12-month treatment with infliximab, a chimeric monoclonal antibody to TNFalpha, had any beneficial effect in reducing relapses of a patient with long-standing $\mathrm{BD}$.

\section{Case presentation}

A 54-year-old woman with a 35-year history of BD was admitted to our Unit. The patient fulfilled the International Study Group criteria for diagnosis of BD [1]. She had a history of recurrent genital and oral aphthous ulcers. Thirty years ago she was diagnosed retinal lesions compatible with vasculitis which lead a few years later to a decrease in visual acuity and blindness in the right eye.

On admission she had orogenital ulcerations, and arthritis in the right knee. The ulcers on the buccal mucosa and tongue were painful with a diameter ranging from 2 to 6 $\mathrm{mm}$. The right knee was swollen with severe functional limitation. She had retinal infiltrates in the left eye. Previ- ous treatment with prednisolone, colchicine, azathioprine and cyclosporin was ineffective and the symptoms recurred periodically.

Erythrocyte sedimentation rate (ESR) was $18.5 \mathrm{~mm} / \mathrm{h}$ and C-reactive protein (CRP) was markedly elevated $(+++)$. CRP levels were measured semiquantitatively and graded negative $(-)$, detectable $(+)$, elevated $(++)$, and markedly elevated $(+++)$. PPD Mantoux test was negative.

Infliximab (Remicade, Centocor Inc, Malvern, PA, Schering Plough SpA, Italy), $5 \mathrm{mg} / \mathrm{kg}$, was administered by a two-hour intravenous infusion.

The patient was observed for 1 hour after stopping infusion and no adverse effects occurred.

An improvement in symptoms was reported within 24 hours after the first infusion. Eight days later the ulcers healed and the arthritis subsided as well. The retinal infiltrates completely resolved within 10 days. A detailed ophthalmological examination was done before and 1, 2, 4,7, $10,14,21,28$ days after the beginning of the treatment; then every 14 days for three months and every 28 days for other eight months.

The infusions were repeated at weeks 2, 6, 14, 22 and then every 8 weeks for 12 months. No other immunosuppressive agent was administered together with infliximab infusions.

After 4 weeks ESR was $15.5 \mathrm{~mm} / \mathrm{h}$ and CRP elevated (++).

The patient was able to return to her domestic daily life.

No exacerbation of the mucocutaneous ocular or arthritic symptoms occurred during the treatment period. After 12 months ESR was $7.5 \mathrm{~mm} / \mathrm{h}$ and CRP detectable (+). Neither serious infections nor development of autoantibodies against double-stranded DNA were observed.

Previous studies have suggested that $\mathrm{BD}$ can be treated effectively with TNF blocking therapy. Infliximab given in a short course of treatment has been reported to be effective in inducing and maintaining remission of BD. Infliximab was successfully administered for treating severe mucocutaneous [10-12], gastrointestinal [13-15] and ocular [16-18] manifestations of $\mathrm{BD}$, with a prompt improvement of long-lasting symptoms which disappeared within a few weeks. The efficacy of infliximab after the failure of etanercept was also reported [19]. Infliximab is a chimeric monoclonal antibody directed against TNFalpha. The antibody binding to soluble TNF-alpha is responsible of the initial dramatic improvement in symptoms after infliximab infusions. 
The longer-lasting effects are related to infliximab binding to transmembrane TNF-alpha expressed on the surface of activated $\mathrm{T}$ cells and macrophages, resulting in lysis of these cells via complement fixation or antibody-dependent cellular toxicity [20].

\section{Conclusions}

It is well known that conventional therapy for BD relies on available anti-inflammatory and immunomodulatory agents, and in view of the scarcity of controlled clinical trials, it is to a large extent empirical [8].

Several case series and single reports have suggested that infliximab given in a short course of treatment is effective in inducing remission of the various manifestations of BD [9-18]. Our patient received a 12-month treatment with a good therapeutic response.

When given in a long-term use infliximab seems to be a useful therapeutic approach for preventing relapses in patients with this disease. In particular the long-term infliximab treatment appears a promising new option for patients with active $\mathrm{BD}$ who failed to respond to conventional immunosuppressive agents.

\section{List of abbreviations used}

$\mathrm{BD}$, Behcet's disease; TNF, tumor necrosis factor; ESR, erythrocyte sedimentation rate; CRP, C-reactive protein.

\section{Competing interests}

None declared.

\section{Authors' contributions}

SG partecipated in the design of the study and drafted the manuscript.

CA partecipated in the systemic examination and collecting data.

LB partecipated in the systemic examination and collecting data.

LM partecipated in the systemic examination and performed laboratory findings.

DS partecipated in the systemic examination and followup visits.

IC carried out the detailed ophthalmological assessment.

GFB conceived of the study, and partecipated in its design and coordination.

All authors read and approved the final manuscript.

\section{Acknowledgements}

Written consent was obtained from the patient for publication of study.

\section{References}

I. International Study Group for Behcet's Disease: Criteria for diagnosis of Behcet's disease. Lancet 1990, 335:1078-1080.

2. Sakane T, Takeno M, Suzuki N and Inaba G: Behcet's disease. N Engl J Med 1999, 34 I:|284-I29|.

3. Gul A: Behcet's disease: an update on the pathogenesis. Clin Exp Rheumatol 200I, 19(suppl):S6-SI2.

4. Turan B, Gallati H, Erdi H, Gurler A, Michel BA and Villiger PM: Systemic levels of the $T$ cell regulatory cytokines IL- 10 and IL12 in Behcet's disease: soluble TNFR-75 as a biologic marker of disease activity. J Rheumatol 1997, 24: I28-132.

5. Yamashita N, Kaneoka H and Kaneko S: Role of gammadelta T lymphocytes in the development of Behcet's disease. Clin Exp Immunol 1997, 107:24I-247.

6. Emmi L, Brugnolo F, Salvati G and Marchione T: Immunopathological aspects of Behcet's disease. Clin Exp Rheumatol 1995, |3:687-69|.

7. Maini R, St Clair EW, Breedveld F, Furst D, Kalden J, Weisman M, Smolen J, Emery P, Harriman G, Feldmann M and Lipsky P: Infliximab (chimeric anti-tumour necrosis factor alpha monoclonal antibody) versus placebo in rheumatic arthritis patients receiving concomitant methotrexate: a randomised phase III trial. Lancet 1999, 354:1932-1939.

8. Kaklamani VG and Kaklamanis PG: Treatment of Behcet's disease: an update. Semin Arthritis Rheum 200I, 30:299-3I2.

9. Sfikakis PP: Behcet's disease: a new target for anti-tumour necrosis factor treatment. Ann Rheum Dis 2002, 6I (suppl II):S5I-S53.

10. Goossens PH, Verburg RJ and Breedveld FC: Remission of Behcet's syndrome with tumour necrosis factor a blocking therapy. Ann Rheum Dis 200I, 60:637.

II. Robertson LP and Hickling P: Treatment of recalcitrant orogenital ulceration of Behcet's syndrome with Infliximab. Rheumatology 200I, 40:473-474.

12. Rozembaum M, Rosner I and Portnoy E: Remission of Behcet's syndrome with TNF alpha blocking treatment. Ann Rheum Dis 2002, 6I:283-284.

13. Hassard PV, Binder SW, Nelson V and Vasiliauskas EA: Anti-tumor necrosis factor monoclonal antibody therapy for gastrointestinal Behcet's disease: a case report. Gastroenterology 200I, 1 20:995-999.

14. Travis SP, Czajkowski M, Mc Govern DP, Watson RG and Bell AL: Treatment of intestinal Behcet's syndrome with chimeric tumour necrosis factor alpha antibody. Gut 200I, 49:725-728.

15. Kram MT, May LD, Goodman S and Molinas S: Behcet's ileocolitis: successful treatment with tumor necrosis factor-alpha antibody (infliximab) therapy: report of a case. Dis Colon Rectum 2003, 46: I| $8-12 \mid$.

16. Sfikakis PP, Theodossiadis PG, Katsiari CG, Kaklamanis P and Markomichelakis NN: Effect of Infliximab on sight-threatening panuveitis in Behcet's disease. Lancet 200I, 358:295-296.

17. Munoz-Fernandez S, Hidalgo V, Fernandez-Melon J, Schlincker A and Martin-Mola E: Effect of Infliximab on threatening panuveitis in Behcet's disease. Lancet 200I, 358:1644.

18. Triolo G, Vadala' M, Accardo Palumbo A, Ferrante A, Ciccia F, Giardina E, Citarrella P, Lodato G and Licata G: Anti-tumour necrosis factor monoclonal antibody treatment for ocular Behcet's disease. Ann Rheum Dis 2002, 61:560-56I.

19. Estrach C, Mpofu S and Moots RJ: Behcet's syndrome: response to infliximab after failure of etanercept. Rheumatology (Oxford) 2002, 4I:|2|3-|2|4.

20. Scallon BJ, Moore MA, Trinh H, Knight DM and Ghrayeb J: Chimeric anti-TNF-alpha monoclonal antibody CA2 binds recombinant transmembrane TNF-alpha and activates immune effector functions. Cytokine 1995, 7:25I-259.

\section{Pre-publication history}

The pre-publication history for this paper can be accessed here: 
http://www.biomedcentral.com/1471-2474/4/19/prepub

Publish with Bio Med Central and every scientist can read your work free of charge

"BioMed Central will be the most significant development for disseminating the results of biomedical research in our lifetime. " Sir Paul Nurse, Cancer Research UK

Your research papers will be:

- available free of charge to the entire biomedical community

- peer reviewed and published immediately upon acceptance

- cited in PubMed and archived on PubMed Central

- yours - you keep the copyright 